\title{
Diet quality among Iranian adolescents needs improvement
}

\author{
Leila Azadbakht ${ }^{1,2, *}$, Fahime Akbari ${ }^{1,2}$ and Ahmad Esmaillzadeh ${ }^{1,2}$ \\ ${ }^{1}$ Food Security Research Center, Isfahan University of Medical Sciences, Isfahan, Islamic Republic of Iran: \\ ${ }^{2}$ Department of Community Nutrition, School of Nutrition and Food Science, Isfahan University of Medical Sciences, \\ Isfahan PO Box 81745, Islamic Republic of Iran
}

Submitted 2 September 2013: Final revision received 24 February 2014: Accepted 11 March 2014: First published online 12 May 2014

\begin{abstract}
Objective: Diet in adolescence is important not only because of adolescents' rapid growth but also due to its influence on future chronic diseases. On the other hand, dietary quality indices are noteworthy and useful approaches to evaluate dietary intakes. Thus the present study was conducted to assess dietary quality indices in adolescents.

Design: Cross-sectional.

Settings: The data were collected from schools in Isfahan, Iran.

Subjects: Female students ( $n$ 265) aged 11-13 years were enrolled using systematic cluster-random sampling in Isfahan (Iran). Dietary intakes were assessed by a validated FFQ. Diet quality indices including dietary diversity score (DDS), the Healthy Eating Index (HEI) and mean adequacy ratio (MAR) across ten nutrients were calculated.

Results: Mean DDS, HEI score and MAR were 6.15 (SD 1.61) out of 10 points, 63.90 (SD 19.86) out of 100 points and 1.32 (SD 0.61), respectively. Mean nutrient adequacy ratio of all nutrients was above 1 except for vitamin $\mathrm{D}(0.53$ (SD 0.51$)$ ). Those in the highest tertile of DDS had the most favourable anthropometric variables in comparison to the lowest tertile. There were no significant associations between HEI score and BMI, central or abdominal obesity and blood pressure. Those in the highest tertile of MAR had higher BMI, waist circumference and hip circumference.

Conclusions: Diet quality of Isfahani adolescents needs improvement. It may imply the necessity of implementing nutritional instructive policies in this age group and their parents.
\end{abstract}

\section{Keywords \\ Diet quality \\ Dietary diversity score Healthy Eating Index}

According to the WHO, adolescents comprise about $19 \%$ of the world's population ${ }^{(1)}$. Although this population needs specific attention due to both adolescents' rapid growth and the influence of their dietary patterns on later life, it is usually neglected ${ }^{(1-3)}$. Dietary intakes during young ages affect physical health and the prevalence of chronic diseases in the future ${ }^{(4)}$. Several studies have shown that overweight and obese adolescents are more prone to be obese ${ }^{(5,6)}$ and to be at risk for $\mathrm{CVD}^{(7,8)}$ later in adulthood. It is well known that the risk of many chronic diseases is associated with dietary pattern during the adolescent years ${ }^{(9,10)}$.

Diet quality indices are an approach to estimate entire diet quality and to assess a person's adherence to dietary guidelines ${ }^{(11)}$. Dietary diversity score (DDS), the Healthy Eating Index (HEI) and mean adequacy ratio (MAR) are $a$ priori-defined diet quality indices.

DDS, often based on a food guide pyramid, focuses on the variety between and within food groups as well ${ }^{(12)}$. Regardless of the fact that eating diverse foods is one key universal prescription for health and nutritional fitness, it has been suggested that diversity within food groups may be better indicator of more healthful outcomes ${ }^{(11)}$. On the other hand, studies showed that DDS is associated with obesity and abdominal adiposity ${ }^{(13)}$, metabolic syndrome $^{(14)}$ and cardiovascular risk factors ${ }^{(15)}$. Moreover, it has been suggested that DDS is a good indicator of adequacy of some nutrients ${ }^{(16)}$.

The HEI, which was designed by the US government to maintain health status and decrease the risk of chronic disease, was established to evaluate adherence to the Dietary Guidelines for Americans ${ }^{(17)}$. The HEI considers consumption of both healthy and unhealthy foods like fruits, vegetables, SFA and cholesterol ${ }^{(17)}$. Studies have shown an inverse correlation between HEI score and different diseases such as abdominal obesity ${ }^{(18)}$, breast cancer ${ }^{(19)}$, pancreatic cancer $^{(20)}$ and high blood pressure ${ }^{(21)}$. Furthermore, HEI score is positively associated with serum folate, vitamin A and vitamin $\mathrm{C}^{(22)}$. 
Nutrient adequacy ratio (NAR) and MAR compare the individual's intake of nutrients with the reference intake. NAR and MAR are specific to age and gender, and therefore may provide more accurate assessment of a person's diet quality ${ }^{(23)}$. Studies have linked NAR and MAR to some unhealthy variables like gastric cancer ${ }^{(24)}$, C-reactive protein $^{(25)}$ and being overweight ${ }^{(26)}$.

Recent evidence shows that the prevalences of overweight and obesity ${ }^{(27)}$ and the metabolic syndrome ${ }^{(28)}$ in Iranian adolescents are relatively high; $15 \cdot 1 \%, 8.3 \%$ and $10 \cdot 1 \%$, respectively. Moreover, the nutrition transition that is taking place in Iran results in an imbalance of dietary intake ${ }^{(29)}$. Regarding these mentioned issues, the risk status of Iranian adolescents and the importance of nutritional measures become revealed.

To our knowledge, studies assessing diet quality indices have mostly been conducted in the adult population, whereas such studies in adolescents are limited. Therefore the aim of present study was to assess diet quality indices including DDS, HEI, MAR and NAR among Isfahani adolescents.

\section{Materials and methods}

\section{Participants}

In the present cross-sectional study, female students aged 11-13 years were recruited by a systematic cluster-random sampling method as a representative sample of female adolescents in Isfahan, Iran. At first, to include districts with different socio-economic status, all districts were involved in sampling. Then several schools were randomly chosen from selected districts. Finally, according to the list of student records of each school, participants were randomly chosen by using a computer-based random sequencing program. At the end, 265 students were enrolled for the statistical analysis.

\section{Assessment of dietary intake}

To evaluate dietary intake, a self-administered semiquantitative FFQ that included fifty-three food items was applied. In the previously published paper among this population, the reliability and validity of this FFQ have been proved ${ }^{(23)}$.

\section{Dietary diversity score}

To score dietary diversity a method introduced by Kant et al. was applied ${ }^{(30)}$. Five main food groups were divided into twenty-three subgroups which show the dietary diversity. Using twenty-three subgroups instead of five main food groups resulted in counting diversity between and within food groups. In addition, a wider range of DDS (i.e. DDS of 10 points rather than 5 points) may be better for comparison of the lowest with the highest group according to diversity. The bread/grains, vegetables, fruits, meat and dairy food groups were categorized into seven (refined bread, biscuits, macaroni, wholegrain bread, corn flakes, rice and refined flour), seven (vegetables, potato, tomato, other starchy vegetables, legumes, yellow vegetables and green vegetables), two (fruit and fruit juice, berries and citrus), four (red meat, poultry, fish and eggs) and three (milk, yoghurt and cheese) subgroups, respectively. To calculate the score for each food group, the sum of scores of the total subgroups was divided into the number of subgroups in its group and then multiplied by 2. Thus DDS could range between 0 and 10 points.

\section{Healthy Eating Index}

The method described by Kennedy et al. was used to

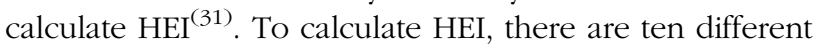
components. The first five components concern the quantity of five groups including grains, vegetables, fruits, milk and meat. The sixth, seventh and eighth components are scored according to the percentage of total fat, SFA and cholesterol intakes. For each component, a maximum score (i.e. 10 points) is given to the diet with $<30 \%$ of energy from total fat, $<10 \%$ energy from SFA and $<300 \mathrm{mg}$ cholesterol. The ninth component concerns dietary variety and the last concerns sodium intake.

\section{Nutrient adequacy ratio}

To calculate NAR, the estimated daily individual intake of each nutrient was divided by the standard recommended amount for the participant's sex and age category according to the nutrient's Dietary Reference Intake $(\mathrm{DRI})^{(32)}$. In the present study NAR values of ten nutrients including $\mathrm{Zn}, \mathrm{Fe}, \mathrm{Ca}$, vitamin $\mathrm{C}$, vitamin $\mathrm{D}$, niacin, vitamin $\mathrm{B}_{12}$, riboflavin, vitamin $\mathrm{B}_{6}$ and vitamin $\mathrm{A}$ were assessed.

\section{Mean adequacy ratio}

MAR was calculated as the ratio of the sum of NAR to the number of nutrients $(n 10)^{(12)}$.

\section{Definition of terms}

Overweight and obesity were considered according to the WHO guidelines as $\mathrm{BMI}=85$ th-95th percentile and BMI > 95th percentile, respectively.

\section{Statistical analysis}

For analysing dietary intakes Nutritionist IV software was used. The SSPS statistical software package version 12 was used for statistical analysis. Cut-off points for DDS, HEI and MAR were calculated and results are presented across tertiles of indices as well. Multivariate ANOVA was used to compare means of continuous variables and the $\chi^{2}$ test was applied to assess the prevalence of overweight/obesity and abdominal obesity across tertiles of indices. ANCOVA that was adjusted for energy intake was used for 
evaluating nutrient intakes among different tertiles. As energy intake is a major confounder for intake of all nutrients and dietary quality indices, it is better to remove the impact of energy intake to better judge the dietary associations.

\section{Results}

Of this adolescent population, $31.3 \%$ were overweight or obese and $38.5 \%$ were abdominally obese. Mean DDS and HEI score were 6.15 (SD 1.61) points and 63.90 (SD 19.86) points, respectively. Mean MAR was 1.32 (SD 0.61); mean of NAR of all nutrients was above 1 except for vitamin $\mathrm{D}$ intake (0.53 (SD 0.51)).

Characteristics and energy-adjusted distribution of nutrient intakes (except for energy intake) among participants across the tertiles of DDS, HEI and MAR are presented in Tables 1, 2 and 3, respectively. Those in the higher tertile of DDS had significantly lower BMI, waist circumference and hip circumference. Prevalences of overweight/obesity and abdominal adiposity were significantly higher in the lowest tertile of DDS. There was no significant association between anthropometric variables and distribution of participants across tertiles of HEI. Participants in the highest tertile of MAR had higher BMI and waist circumference. Adolescents in the highest tertile of DDS compared with the lowest tertile had lower intakes of energy, total fat and SFA, and higher intakes of protein, vitamin $\mathrm{A}$, vitamin $\mathrm{D}$, vitamin $\mathrm{B}_{6}$, folate, $\mathrm{Zn}, \mathrm{K}, \mathrm{Ca}, \mathrm{Mg}$ and vitamin $\mathrm{B}_{12}$. Those in the highest tertile of HEI had significantly higher intakes of protein, vitamin $\mathrm{D}$, vitamin $\mathrm{C}$, folate, vitamin $\mathrm{B}_{12}, \mathrm{~K}, \mathrm{Ca}, \mathrm{Mg}$ and $\mathrm{Zn}$, and lower intake of cholesterol. Adolescents in the highest tertile of MAR had higher intakes of energy, protein and cholesterol and lower intakes of total fat and SFA.

\section{Discussion}

In the present study dietary indices approximately had significant associations with anthropometric variables and nutrient intakes. DDS had the most favourable associations.

One study conducted in Tehran, Iran showed similar mean DDS for adolescents, although $24 \mathrm{~h}$ recalls were

Table 1 Characteristics and energy-adjusted distribution of nutrient intakes across tertiles of dietary diversity score* (DDS) among female adolescents $(n 265)$ aged $11-13$ years, Isfahan, Iran

\begin{tabular}{|c|c|c|c|c|c|c|c|}
\hline & \multicolumn{6}{|c|}{ Tertile categories of DDS } & \multirow[b]{3}{*}{$P \dagger$} \\
\hline & \multicolumn{2}{|c|}{$1(n 40)$} & \multicolumn{2}{|c|}{$2(n 128)$} & \multicolumn{2}{|c|}{$3(n 97)$} & \\
\hline & Mean or \% & SD & Mean or $\%$ & SD & Mean or $\%$ & SD & \\
\hline Height $(\mathrm{cm})$ & $153 \cdot 81 \S$ & $7 \cdot 11$ & $152 \cdot 23$ & $7 \cdot 63$ & $149 \cdot 61$ & $8 \cdot 11$ & 0.006 \\
\hline Weight (kg) & 51.06 & $10 \cdot 98$ & $46 \cdot 31$ & $9 \cdot 31$ & $42 \cdot 21$ & $10 \cdot 01$ & $<0.001$ \\
\hline BMI $\left(\mathrm{kg} / \mathrm{m}^{2}\right)$ & 21.47 & 3.60 & 19.83 & 2.99 & 18.69 & 3.32 & $<0.001$ \\
\hline Overweight or obesity (\%) & $50 \cdot 0$ & - & $31 \cdot 3$ & - & 23.7 & - & 0.01 \\
\hline Waist circumference (cm) & 72.92 & $10 \cdot 46$ & 68.98 & 7.98 & $66 \cdot 24$ & 8.66 & $<0.001$ \\
\hline Hip circumference (cm) & 87.66 & $7 \cdot 79$ & 84.63 & $7 \cdot 25$ & 80.93 & 8.58 & $<0.001$ \\
\hline Abdominal adiposity (\%) & $60 \cdot 0$ & - & $42 \cdot 2$ & - & $24 \cdot 7$ & - & $<0.001$ \\
\hline \multicolumn{8}{|l|}{ Nutrients } \\
\hline Energy intake (kJ)‡ & $11570 \cdot 51$ & $926 \cdot 24$ & $10586 \cdot 24$ & $1005 \cdot 73$ & $8836 \cdot 16$ & $907 \cdot 82$ & $<0.001$ \\
\hline Energy intake $(\mathrm{kcal}) \ddagger$ & 2763.57 & 221.23 & 2528.48 & $240 \cdot 21$ & 2110.48 & 216.83 & $<0.001$ \\
\hline Protein $(\mathrm{g})$ & 65.91 & 17.97 & 73.52 & $17 \cdot 85$ & 81.76 & $18 \cdot 11$ & $<0.001$ \\
\hline Carbohydrate (g) & $349 \cdot 32$ & $47 \cdot 41$ & 347.05 & $47 \cdot 10$ & $362 \cdot 14$ & $47 \cdot 78$ & 0.06 \\
\hline Fat $(g)$ & 87.01 & 23.48 & $85 \cdot 24$ & 23.33 & 74.90 & 23.67 & 0.002 \\
\hline SFA (g) & $25 \cdot 69$ & 7.44 & $24 \cdot 39$ & $7 \cdot 39$ & 23.04 & 7.49 & 0.15 \\
\hline Cholesterol (mg) & 157.61 & 90.03 & $170 \cdot 80$ & 89.50 & 185.93 & $90 \cdot 72$ & 0.22 \\
\hline $\mathrm{Na}(\mathrm{mg})$ & $2445 \cdot 84$ & 528.88 & $2451 \cdot 34$ & 525.43 & 2439.11 & 532.93 & 0.99 \\
\hline Vitamin A $(\mu \mathrm{g})$ & 461.87 & $405 \cdot 01$ & $615 \cdot 67$ & $402 \cdot 36$ & 696.57 & $408 \cdot 12$ & 0.01 \\
\hline Vitamin D $(\mu \mathrm{g})$ & $1 \cdot 81$ & $2 \cdot 29$ & $2 \cdot 66$ & $2 \cdot 28$ & $2 \cdot 97$ & $2 \cdot 31$ & 0.03 \\
\hline Vitamin C (mg) & 42.49 & $49 \cdot 71$ & $54 \cdot 94$ & $49 \cdot 38$ & 55.99 & 50.09 & 0.32 \\
\hline Niacin (mg) & 14.33 & 3.77 & 14.85 & 3.76 & 14.49 & 3.80 & 0.65 \\
\hline Vitamin $B_{6}(\mathrm{mg})$ & 1.08 & 0.31 & $1 \cdot 19$ & 0.30 & $1 \cdot 26$ & 0.31 & 0.02 \\
\hline Folate $(\mu \mathrm{g})$ & $199 \cdot 49$ & 49.99 & $227 \cdot 95$ & 49.67 & $244 \cdot 18$ & $50 \cdot 38$ & $<0.001$ \\
\hline Vitamin $B_{12}(\mu \mathrm{g})$ & $2 \cdot 36$ & $1 \cdot 11$ & 2.75 & $1 \cdot 10$ & 3.25 & $1 \cdot 11$ & $<0.001$ \\
\hline $\mathrm{K}(\mathrm{mg})$ & $2834 \cdot 35$ & $910 \cdot 79$ & $3250 \cdot 14$ & 904.84 & $3678 \cdot 33$ & $917 \cdot 72$ & $<0.001$ \\
\hline $\mathrm{Ca}(\mathrm{mg})$ & $1198 \cdot 23$ & 605.06 & 1441.07 & $601 \cdot 11$ & 1735.60 & $609 \cdot 70$ & $<0.001$ \\
\hline $\mathrm{Fe}(\mathrm{mg})$ & 8.93 & $2 \cdot 10$ & 9.48 & $2 \cdot 08$ & $9 \cdot 21$ & $2 \cdot 12$ & 0.31 \\
\hline $\mathrm{Mg}(\mathrm{mg})$ & 237.08 & 64.19 & 275.81 & 63.76 & 295.93 & 64.68 & $<0.001$ \\
\hline $\mathrm{Zn}(\mathrm{mg})$ & 8.07 & 2.63 & 9.02 & $2 \cdot 61$ & $10 \cdot 16$ & 2.65 & $<0.001$ \\
\hline
\end{tabular}

*Tertile cut-off points of DDS are as follows: first, $\leq 4.999$; second, 5.000 to 7.999 ; third, $\geq 8.000$

$\dagger P$ values resulting from ANOVA for quantitative variables and from $\chi^{2}$ test for qualitative variables.

‡Energy was not adjusted for energy intake.

$\S$ Values are presented as mean and standard deviation unless indicated otherwise. 
Table 2 Characteristics and energy-adjusted distribution of nutrient intakes across tertiles of the Healthy Eating Index (HEI) among female adolescents $(n 265)$ aged $11-13$ years, Isfahan, Iran

\begin{tabular}{|c|c|c|c|c|c|c|c|}
\hline & \multicolumn{6}{|c|}{ Tertile categories of $\mathrm{HEI}$} & \multirow[b]{3}{*}{$P+$} \\
\hline & \multicolumn{2}{|c|}{$1(n 71)$} & \multicolumn{2}{|c|}{$2(n$ 104) } & \multicolumn{2}{|c|}{$3(n 90)$} & \\
\hline & Mean or $\%$ & SD & Mean or \% & SD & Mean or \% & SD & \\
\hline Height (cm) & $152.93 \S$ & $6 \cdot 85$ & $151 \cdot 24$ & 8.02 & $150 \cdot 69$ & 8.33 & 0.18 \\
\hline Weight (kg) & $47 \cdot 40$ & 9.62 & 44.70 & $10 \cdot 40$ & 44.99 & 10.46 & 0.19 \\
\hline $\operatorname{BMI}\left(\mathrm{kg} / \mathrm{m}^{2}\right)$ & $20 \cdot 17$ & 3.15 & $19 \cdot 34$ & 3.31 & 19.63 & 3.48 & 0.27 \\
\hline Overweight or obesity (\%) & 31.0 & - & $26 \cdot 9$ & - & $36 \cdot 7$ & - & 0.34 \\
\hline Waist circumference (cm) & $70 \cdot 18$ & 9.26 & 68.40 & 8.65 & 67.51 & 8.79 & 0.16 \\
\hline Hip circumference $(\mathrm{cm})$ & $85 \cdot 22$ & 7.23 & 82.96 & 8.40 & 83.44 & 8.52 & 0.18 \\
\hline Abdominal adiposity (\%) & $47 \cdot 9$ & - & $36 \cdot 5$ & - & 33.3 & - & 0.15 \\
\hline \multicolumn{8}{|l|}{ Nutrients } \\
\hline Energy intake $(\mathrm{kJ}) \ddagger$ & $10582 \cdot 68$ & $1003 \cdot 33$ & $9730 \cdot 12$ & 971.60 & $10129 \cdot 63$ & 989.05 & 0.40 \\
\hline Energy intake (kcal) $\ddagger$ & 2527.63 & 239.64 & 2324.00 & 232.06 & $2419 \cdot 42$ & $236 \cdot 23$ & 0.40 \\
\hline Protein $(\mathrm{g})$ & 68.89 & $18 \cdot 18$ & 77.25 & $18 \cdot 18$ & 78.36 & $18 \cdot 15$ & 0.002 \\
\hline Carbohydrate (g) & 347.67 & 47.24 & 359.39 & $47 \cdot 22$ & 349.58 & $47 \cdot 14$ & 0.20 \\
\hline Fat $(g)$ & 86.78 & 23.58 & 78.06 & 23.58 & 81.95 & 23.55 & 0.06 \\
\hline SFA (g) & 25.41 & 7.35 & $22 \cdot 72$ & 7.34 & 24.64 & 7.33 & 0.04 \\
\hline Cholesterol (mg) & 291.23 & $36 \cdot 34$ & 243.12 & $23 \cdot 17$ & 217.54 & $19 \cdot 32$ & 0.01 \\
\hline $\mathrm{Na}(\mathrm{mg})$ & $2419 \cdot 19$ & 523.36 & 2422.58 & $523 \cdot 18$ & 2494.31 & $522 \cdot 38$ & 0.56 \\
\hline Vitamin $A(\mu \mathrm{g})$ & 533.87 & $404 \cdot 86$ & 672.01 & 404.72 & 633.92 & $404 \cdot 10$ & 0.08 \\
\hline Vitamin $D(\mu \mathrm{g})$ & 6.51 & $2 \cdot 14$ & 6.77 & $2 \cdot 26$ & $7 \cdot 11$ & 2.36 & 0.39 \\
\hline Vitamin C (mg) & 101.43 & 21.54 & $113 \cdot 15$ & $23 \cdot 13$ & $131 \cdot 34$ & $25 \cdot 56$ & 0.11 \\
\hline Niacin (mg) & 14.94 & 3.74 & 14.75 & 3.74 & $14 \cdot 28$ & 3.74 & 0.50 \\
\hline Vitamin $\mathrm{B}_{6}(\mathrm{mg})$ & $1 \cdot 15$ & 0.31 & 1.24 & 0.32 & $1 \cdot 19$ & 0.31 & 0.18 \\
\hline Folate $(\mu \mathrm{g})$ & 213.67 & $50 \cdot 72$ & 235.52 & $50 \cdot 70$ & $235 \cdot 31$ & $50 \cdot 63$ & 0.009 \\
\hline Vitamin $\mathrm{B}_{12}(\mu \mathrm{g})$ & 2.48 & 1.11 & 2.97 & 1.11 & 3.08 & 1.11 & 0.002 \\
\hline $\mathrm{K}(\mathrm{mg})$ & 3028.02 & $927 \cdot 14$ & 3472.95 & 926.81 & 3444.60 & 925.39 & 0.004 \\
\hline $\mathrm{Ca}(\mathrm{mg})$ & 1275.20 & 610.71 & 1578.90 & 610.49 & 1622.17 & 609.56 & 0.001 \\
\hline $\mathrm{Fe}(\mathrm{mg})$ & 9.21 & 2.08 & 9.52 & 2.08 & $9 \cdot 11$ & 2.08 & 0.36 \\
\hline $\mathrm{Mg}(\mathrm{mg})$ & 253.81 & 64.82 & 288.34 & 64.80 & $283 \cdot 16$ & $64 \cdot 70$ & 0.002 \\
\hline $\mathrm{Zn}(\mathrm{mg})$ & 8.39 & 2.65 & 9.66 & 2.65 & 9.59 & 2.65 & 0.004 \\
\hline
\end{tabular}

${ }^{*}$ Tertile cut-off points of HEI are as follows: first, $\leq 53.999$; second, 54.000 to $77 \cdot 119$; third, $\geq 77 \cdot 120$.

$\dagger P$ values resulting from ANOVA for quantitative variables and from $\chi^{2}$ test for qualitative variables.

fEnergy was not adjusted for energy intake.

$\S$ Values are presented as mean and standard deviation unless indicated otherwise.

used in the mentioned study that might be associated with a large amount of under-reporting and over-reporting ${ }^{(12)}$. Kersting et al. reported that 50-80\% of 13-16-year-old adolescents had the full score of 5 for DDS; however, that group also used a $24 \mathrm{~h}$ recall for assessing nutritional intake ${ }^{(33)}$. Different scoring patterns could be the reason for different results. DDS calculated in the present paper has two strengths. The first is that, in contrast to most previous studies, DDS was quantified based on FFQ rather than dietary recall. To evaluate DDS, FFQ is the more applicable instrument since diet diversity is regarded as a long dietary exposure. The second point is that to calculate DDS we derived twenty-three subgroups from five main food groups; counting twenty-three food subgroups resulted in reaching more accurate DDS as it represented the diversity of food groups as well as the diversity within food groups.

The mean HEI score in the present study is consistent with some earlier studies that were carried out with the same method to calculate HEI in this age group ${ }^{(34,35)}$. One study reported 51.5 (SD 9.07) points as the mean HEI score $^{(36)}$. However, those authors used $24 \mathrm{~h}$ recall and HEI-2005 to evaluate dietary intakes. Feskanich et al. introduced the Youth Healthy Eating Index (YHEI) that is a modified HEI to assess diet quality in adolescents ${ }^{(17)}$. Apart from HEI components, YHEI also focuses on foods that are high sources of trans-fatty acids or added sugars or low sources of fibre. Therefore YHEI can range from 0 to 100 points and consists of thirteen components including whole grains, vegetables, fruits, dairy, meat ratio, snack foods, soda and drinks, multivitamin use, margarine and butter, fried foods outside home, visible animal fat, and eat breakfast and dinner with family; components 1 to 7 and 8 to 13 score up to 10 and 5 points, respectively ${ }^{(17)}$. In their study on 16452 participants aged 9-14 years, mean HEI was 68.9 to 73.2 points, whereas mean YHEI was 58.6 and 59.6 points (for boys and girls, respectively). Information regarding the trans-fat content of foods is not available in Iran, so it is impossible to calculate YHEI scores unless accounting for trans-fat sources instead of trans-fat content of foods.

In a study with 2855 Spanish subjects aged 2 to 24 years, most NAR were 1.0 or below but near 1 , except for vitamin D (0.36), vitamin E (0.66) and vitamin A (0.67) which had the lowest $\mathrm{NAR}^{(37)}$. In the present study also vitamin D and vitamin A had the lowest NAR values but both were above 1 . In addition, it should be noted that in 
Table 3 Characteristics and energy-adjusted distribution of nutrient intakes across tertiles of mean adequacy ratio* (MAR) among female adolescents $(n$ 265) aged $11-13$ years, Isfahan, Iran

\begin{tabular}{|c|c|c|c|c|c|c|c|}
\hline & \multicolumn{6}{|c|}{ Tertile categories of MAR } & \multirow[b]{3}{*}{$P+$} \\
\hline & \multicolumn{2}{|c|}{$1(n 84)$} & \multicolumn{2}{|c|}{$2(n 88)$} & \multicolumn{2}{|c|}{$3(n 92)$} & \\
\hline & Mean or \% & SD & Mean or \% & SD & Mean or \% & SD & \\
\hline Height (cm) & $152 \cdot 29 \S$ & 7.64 & $150 \cdot 44$ & 8.42 & $151 \cdot 76$ & 7.49 & 0.28 \\
\hline Weight $(\mathrm{kg})$ & $42 \cdot 82$ & $9 \cdot 10$ & 44.48 & $10 \cdot 04$ & $49 \cdot 06$ & 10.57 & $<0.001$ \\
\hline BMI $\left(\mathrm{kg} / \mathrm{m}^{2}\right)$ & 18.30 & $2 \cdot 50$ & 19.53 & 3.36 & 21.08 & 3.42 & $<0.001$ \\
\hline Overweight or obesity (\%) & 21.4 & - & $31 \cdot 8$ & - & $40 \cdot 2$ & - & 0.25 \\
\hline Waist circumference (cm) & 66.19 & 8.55 & 68.00 & 8.93 & 71.40 & 8.47 & $<0.001$ \\
\hline Hip circumference (cm) & 81.72 & $7 \cdot 10$ & 82.87 & 8.06 & 86.45 & 8.55 & $<0.001$ \\
\hline Abdominal adiposity (\%) & $33 \cdot 3$ & - & $30 \cdot 7$ & - & $51 \cdot 1$ & - & 0.01 \\
\hline \multicolumn{8}{|l|}{ Nutrients } \\
\hline Energy intake $(\mathrm{kJ}) \ddagger$ & $6513 \cdot 19$ & $415 \cdot 80$ & $9360 \cdot 05$ & 585.46 & $14080 \cdot 37$ & 843.32 & $<0.001$ \\
\hline Energy intake (kcal)‡ & 1555.65 & 99.31 & 2235.61 & 139.83 & 3363.04 & 201.42 & $<0.001$ \\
\hline Protein $(\mathrm{g})$ & 60.94 & $20 \cdot 25$ & $70 \cdot 35$ & $16 \cdot 39$ & 93.68 & 21.50 & $<0.001$ \\
\hline Carbohydrate (g) & 348.63 & 58.64 & 345.46 & 47.45 & $365 \cdot 19$ & $62 \cdot 24$ & 0.07 \\
\hline Fat $(\mathrm{g})$ & 88.97 & 28.54 & $87 \cdot 84$ & 23.09 & 68.95 & 30.29 & $<0.001$ \\
\hline SFA (g) & 24.57 & $9 \cdot 19$ & $25 \cdot 54$ & 7.44 & $22 \cdot 28$ & $9 \cdot 75$ & 0.05 \\
\hline Cholesterol (mg) & 113.46 & 103.02 & $165 \cdot 81$ & 83.96 & 238.77 & $110 \cdot 21$ & $<0.001$ \\
\hline $\mathrm{Na}(\mathrm{mg})$ & 2489.89 & 653.99 & 2390.49 & $529 \cdot 16$ & 2465.52 & 694.11 & 0.43 \\
\hline Vitamin A $(\mu \mathrm{g})$ & $326 \cdot 58$ & 469.90 & $590 \cdot 41$ & $380 \cdot 21$ & 924.07 & 498.73 & $<0.001$ \\
\hline Vitamin D $(\mu \mathrm{g})$ & 1.63 & 2.66 & 1.96 & $2 \cdot 18$ & 4.23 & $2 \cdot 78$ & $<0.001$ \\
\hline Vitamin C (mg) & $32 \cdot 17$ & 59.57 & $50 \cdot 61$ & 48.59 & $75 \cdot 82$ & 63.69 & $<0.001$ \\
\hline $\operatorname{Niacin}(\mathrm{mg})$ & 14.80 & 4.67 & 14.22 & 3.78 & 14.94 & 4.96 & 0.43 \\
\hline Vitamin $B_{6}(\mathrm{mg})$ & 0.93 & 0.34 & $1 \cdot 12$ & 0.27 & 1.52 & 0.35 & $<0.001$ \\
\hline Folate $(\mu \mathrm{g})$ & 189.67 & 58.34 & 223.73 & 47.20 & 271.64 & 61.91 & $<0.001$ \\
\hline Vitamin $B_{12}(\mu \mathrm{g})$ & 1.91 & 1.21 & 2.55 & 0.97 & 4.08 & 1.28 & $<0.001$ \\
\hline $\mathrm{K}(\mathrm{mg})$ & 2353.65 & 936.91 & $3107 \cdot 68$ & 758.08 & 4478.64 & 994.39 & $<0.001$ \\
\hline $\mathrm{Ca}(\mathrm{mg})$ & 998.06 & 677.78 & $1350 \cdot 78$ & 548.41 & 2141.93 & 719.35 & $<0.001$ \\
\hline $\mathrm{Fe}(\mathrm{mg})$ & 9.05 & 2.59 & 9.01 & $2 \cdot 10$ & $9 \cdot 83$ & 2.75 & 0.10 \\
\hline $\mathrm{Mg}(\mathrm{mg})$ & 213.42 & $68 \cdot 36$ & $261 \cdot 15$ & $55 \cdot 32$ & 351.54 & 72.56 & $<0.001$ \\
\hline $\mathrm{Zn}(\mathrm{mg})$ & $6 \cdot 83$ & 2.85 & 8.67 & $2 \cdot 31$ & $12 \cdot 17$ & 3.03 & $<0.001$ \\
\hline
\end{tabular}

*Tertile cut-off points of MAR are as follows: first, $\leq 0.979$; second, 0.980 to 1.389; third, $\geq 1.390$.

$\dagger P$ values resulting from ANOVA for quantitative variables and from $\chi^{2}$ test for qualitative variables.

‡Energy was not adjusted for energy intake.

$\S$ Values are presented as mean and standard deviation unless indicated otherwise.

Serra-Majem et al.'s study there was a wide variation in energy and nutrient intakes by age group, among which the 14-17-year-olds and then 10-13-year-olds were at higher risk for inadequate nutrient intakes. So it could be concluded that adolescents had the lower NAR compared with children and young adults. With regard to excluding just under-reporters in the previous study, higher NAR of the present study might be conflicting to some extent.

In our study population, those in the highest compared with the lowest tertile of the three indices had higher protein and carbohydrate intakes, and lower fat and SFA intakes. In contrast, cholesterol pattern was inconsistent between the three dietary indices; cholesterol intake was higher in the third tertile of DDS and MAR whereas across tertiles of HEI cholesterol intake decreased. These could be explained by components of scoring, as DDS was calculated based on sources of protein and carbohydrate but sources of fat did not count in diversity scoring. Moreover, sources of cholesterol like eggs are included in DDS; meanwhile, main sources of SFA such as hydrogenated oil and butter did not enter into the scoring pattern. Participants in the third tertile of HEI had lower fat, SFA and cholesterol intakes in comparison to the lowest tertile because the mentioned items are independent components of the HEI. Patterns observed across tertiles of MAR could be probably attributed to the sources of the evaluated vitamin; for example, meat is the source of $\mathrm{Zn}$ and $\mathrm{Fe}$ and the highest tertile of MAR received more protein, or although eggs are a source of vitamin A they contain a high amount of cholesterol.

There are some limitations to the present study. To evaluate dietary intakes an FFQ with fifty-three food items was applied; it may not reflect the exact intakes to some extent. However, the reliability and validity of this questionnaire were proved. Results of the present study may not accurately extrapolate to all Iranian adolescents due to small sample size as well as single gender. In addition, the age range is narrowed down to 11-13-year-old girls. All three indices assess overall diet quality while each index considers a different aspect of diet. Generally, DDS is more focused on the dietary diversity, HEI is focused on food intakes and MAR assesses the micronutrient intakes. MAR is important because the adequacy of each micronutrient is necessary for metabolic pathways in the body. On the other hand, due to the interaction between different components of diet, more comprehensive 
observations should be considered like HEI and DDS. Therefore regarding these three indices together could result in a better judgement of diet quality.

\section{Conclusion}

The quality of Iranian adolescents' diet needs improvement; indeed, dietary quality is the major problem, not dietary quantity, in Isfahani adolescents.

\section{Acknowledgements}

Acknowledgements: The authors are grateful to the participants of the present study for their enthusiastic cooperation. Sources of funding: This study was funded by the Food Security Research Center, Isfahan University of Medical Sciences (IUMS), Isfahan, Iran. The authors would like to express their appreciation to the Research Council of IUMS for financial support of the study. The Research Council of IUMS had no role in the design, analysis or writing of this article. Conflict of interest: None. Authorship: L.A. and A.E. designed the study and collected the data. F.A. wrote the manuscript. L.A. analysed the data and read the draft of the manuscript, commented on it and revised it. All authors read the final version of the manuscript and approved the final version. Ethics of human subject participation: The Ethical Committee of IUMS has approved this study.

\section{References}

1. World Health Organization (2011) Adolescent nutrition: a neglected dimension. https://apps.who.int/nut/ado.htm (accessed September 2011).

2. Stang J \& Story M (editors) (2005) Guidelines for Adolescent Nutrition Services. Minneapolis, MN: Center for Leadership, Education and Training in Maternal and Child Nutrition, Division of Epidemiology and Community Health, School of Public Health, University of Minnesota.

3. Delisle H (2005) Nutrition in Adolescence - Issues and Challenges for the Health Sector. Geneva: WHO.

4. Krinke U (2002) Adult nutrition. In Nutrition Through the Life Cycle, pp. 383-407 [J Brown, editor]. Belmont, CA: Wadsworth/Thomson Learning.

5. Serdula MK, Ivery D, Coates RJ et al. (1993) Do obese children become obese adults? A review of the literature. Prev Med 22, 167-177.

6. Whitaker RC, Wright JA, Pepe MS et al. (1997) Predicting obesity in young adulthood from childhood and parental obesity. $N$ Engl J Med 337, 869-873.

7. Bibbins-Domingo K, Coxson P, Pletcher JM et al. (2007) Adolescent overweight and future adult coronary heart disease. $N$ Engl J Med 357, 2371-2379.

8. Falkstedt D, Hemmingsson T, Rasmussen F et al. (2007) Body mass index in late adolescence and its association with coronary heart disease and stroke in middle age among Swedish men. Int J Obes (Lond) 31, 777-783.

9. Sandler RB, Slemenda CW, LaPorte RE et al. (1985) Postmenopausal bone density and milk consumption in childhood and adolescence. Am J Clin Nutr 42, 270-274.
10. Weaver MC, Peacock M \& Johnston CC (1999) Adolescent nutrition in the prevention of postmenopausal osteoporosis. $J$ Clin Endocrinol Metab 84, 1839-1843.

11. Wirt A \& Collins CE (2009) Diet quality - what is it and does it matter? Public Health Nutr 12, 2473-2492.

12. Mirmiran P, Azadbakht L, Esmaillzadeh A et al. (2004) Dietary diversity score in adolescents - a good indicator of the nutritional adequacy of diets: Tehran Lipid and Glucose Study. Asia Pac J Clin Nutr 13, 56-60.

13. Azadbakht L \& Esmaillzadeh A (2011) Dietary diversity score is related to obesity and abdominal adiposity among Iranian female youth. Public Health Nutr 14, 62-69.

14. Azadbakht L, Mirmiran P \& Azizi F (2005) Dietary diversity score is favorably associated with the metabolic syndrome in Tehranian adults. Int J Obes (Lond) 29, 1361-1367.

15. Azadbakht L, Mirmiran P, Esmaillzadeh A et al. (2006) Dietary diversity score and cardiovascular risk factors in Tehranian adults. Public Health Nutr 9, 728-736.

16. Mirmiran P, Azadbakht L \& Azizi F (2006) Dietary diversity within food groups: an indicator of specific nutrient adequacy in Tehranian women. J Am Coll Nutr 25, 354-361.

17. Feskanich D, Rockett HR \& Colditz GA (2004) Modifying the Healthy Eating Index to assess diet quality in children and adolescents. J Am Diet Assoc 104, 1375-1383.

18. Tande DL, Magel R \& Strand BN (2010) Healthy Eating Index and abdominal obesity. Public Health Nutr 13, 208-214

19. Shahril MR, Sulaiman S, Shaharudin SH et al. (2013) Healthy eating index and breast cancer risk among Malaysian women. Eur J Cancer Prev 22, 342-347.

20. Arem H, Reedy J, Sampson J et al. (2013) The Healthy Eating Index 2005 and risk for pancreatic cancer in the NIHAARP study. J Natl Cancer Inst 105, 1298-1305.

21. Haghighatdoost F, Sarrafzadegan N, Mohammadifard N et al. (2013) Healthy eating index and cardiovascular risk factors among Iranians. J Am Coll Nutr 32, 111-121.

22. Weinstein SJ, Vogt TM \& Gerrior SA (2004) Healthy Eating Index scores are associated with blood nutrient concentrations in the third National Health and Nutrition Examination Survey. J Am Diet Assoc 104, 576-584.

23. Rouhani MH, Mirseifinezhad M, Omrani N et al. (2012) Fast food consumption, quality of diet, and obesity among Isfahanian adolescent girls. $J$ Obes 2012, 8 .

24. Lim H, Cho G \& Kim S (2012) Evaluation of nutrient intake and diet quality of gastric cancer patients in Korea. Nutr Res Pract 6, 213-220.

25. Kuczmarski MF, Mason MA, Allegro D et al. (2013) Diet quality is inversely associated with C-reactive protein levels in urban, low-income African-American and white adults. J Acad Nutr Diet 113, 1620-1631.

26. Yu CH \& Lee JS (2004) A study on the nutritional status according to body mass index in Korean college women. Korean J Nutr 37, 899-907.

27. Hajian-Tilaki K \& Heidari B (2012) Prevalences of overweight and obesity and their association with physical activity pattern among Iranian adolescents aged 12-17 years. Public Health Nutr 15, 2246-2252.

28. Esmaillzadeh A, Mirmiran P, Azadbakht L et al. (2006) High prevalence of the metabolic syndrome in Iranian adolescents. Obesity (Silver Spring) 14, 337-382.

29. Ghassemi H, Harrison G \& Mohammad K (2002) An accelerated nutrition transition in Iran. Public Health Nutr $\mathbf{5}$, 149-155.

30. Kant AK, Schatzkin A \& Ziegler RG (1995) Dietary diversity and subsequent cause of specific mortality in the NHANES I epidemiologic follow-up study. J Am Coll Nutr 14, 233-238.

31. Kenndy ET, Ohls J, Carlson S et al. (1995) The Healthy Eating Index: design and applications. J Am Diet Assoc 95, 1103-1108. 
32. Escott-Stump S \& Mahan L (2008) Dietary Reference Intakes (DRIs): recommended intakes for individuals, vitamin/ mineral. In Krause's Food \& Nutrition Therapy, 12th ed. pp. Prefix:1-3. Philadelphia, PA: Saunders Elsevier.

33. Kersting M, Sichert-Hellert W, Vereecken CA et al. (2008) Food and nutrient intake, nutritional knowledge and dietrelated attitudes in European adolescents. Int J Obes (Lond) 32, 35-41.

34. Hurley KM, Oberlander SE, Merry BC et al. (2009) The healthy eating index and youth healthy eating index are unique, nonredundant measures of diet quality among low-income, African American adolescents. J Nutr 139, 359-364.

35. Mirmiran P, Azadbakht L \& Azizi F (2004) Healthy eating index and its relation with diet quality in Tehrani adolescents: Tehran Lipid and Glucose Study. J Res Med Sci 1, 829-838.

36. Tek NA, Yildiran H, Akbulut G et al. (2011) Evaluation of dietary quality of adolescents using Healthy Eating Index. Nutr Res Pract 5, 322-328.

37. Serra-Majem L, Ribas-Barba L, Pérez-Rodrigo C et al. (2006) Nutrient adequacy in Spanish children and adolescents. BrJ Nutr 96, 49-57. 